\title{
SULODEXIDE IN THE TREATMENT OF VASCULAR DISEASE: ITS THERAPEUTIC ACTION ON THE ENDOTHELIUM
}

\author{
Karolina Jarząbek, Bożena Gabryel, Tomasz Urbanek \\ Department of Pharmacology, Medical University of Silesia, Katowice, Poland \\ Department of General Surgery, Vascular Surgery, Angiology and Phlebology, Medical \\ University of Silesia, Poland
}

\section{REVIEW PAPER}

Phlebological Review 2016; 24, 4: 51-59

DOl: https://doi.org/10.5114/pr.2016.67742

Submitted: 12.10 .2016

Accepted: 26.11.2016

\author{
ADDRESS FOR CORRESPONDENCE \\ Karolina Jarząbek \\ Department of Pharmacology \\ Medical University of Silesia \\ Medyków 18 \\ 40-752 Katowice, Poland \\ e-mail: karojarz@gmail.com
}

\begin{abstract}
Sulodexide (SDX) is a mixture of highly purified glycosaminoglycans (GAGs), consisting of $80 \%$ fast-moving heparin (FMH) and $20 \%$ dermatan sulfate (DS). Recently but also many other vascular disorders. The efficacy of SDX in the treatment of peripheral arterial disease (PAD) or diabetic nephropathy has also been demonstrated. The way that SDX operates on the biology of vascular endothelial cells is not fully understood. It has anticoagulant, profibrinolytic and anti-aggregative properties. Moreover, it delivers substrates for the reconstruction of vascular endothelial glycocalyx and, at the same time, inhibits the activity of enzymes responsible for cleaving GAGs. Besides its effects on the glycocalyx, which is located on the surface of endothelium, part of a dose penetrates the endothelial cells and has an effect on the expression of multiple growth factors. It has been observed that SDX has protective, reparative, anti-inflammatory, anti-oxidant, anti-apoptotic and an anti-atherosclerotic influence on vascular endothelial cells. In this review article, each of these aspects of SDX's activity has been thoroughly discussed in the context of chronic venous disease. Special regard was dedicated to the increasing amount of reports about the high efficiency of SDX in the treatment of patients with CVD at various stages. Sulodexide has a wide therapeutic range in the treatment of vascular disorders. Further research is needed to explain the precise mechanism of action of this pleiotropic drug.
\end{abstract}

Key words: chronic venous disease, endothelium, sulodexide, Glycocalyx.

\section{INTRODUCTION}

The endothelium is a single layer of cells which lines the internal surface of each type of blood vessel. It is not merely a physical barrier separating the stream of blood from the highly reactive subendothelial connective tissue, but it plays an important role in the maintenance of normal vascular haemostasis. It synthesizes a variety of substances that inhibit blood coagulation and platelet aggregation, regulates the tension and permeability of the vascular wall and is responsible for balanced fibrinolysis through inhibitors and activators. The most important anticoagulant mechanisms of endothelium include: (1) the glycocalyx, consisting of heparan sulfate (HS) which has potent anticoagulant properties (2) a fundamental expression of the tissue factor pathway inhibitor (TFPI) (3) a protein C system containing thrombomodulin (TM) which is synthesized by the endothelium (4) the synthesis of tissue plasminogen activator (tPA) and urokinase-type plasminogen activator (uPA) and (5) the secretion of nitric oxide (NO) and prostacyclin, which despite its vasodilator activity has the ability to inhibit platelet aggregation. Under physiological conditions the endothelium has strong anticoagulant properties. However, after activation it becomes a place of synthesis and the expression of many adhesion molecules, chemokines and chemokine receptors. Endothelial cells activation is followed by thrombin activation, under the influence of pro-inflammatory cytokines such as tumour necrosis factor (TNF), interleukin-1 $\beta$ (IL-1 $\beta$ ) or under ischaemic conditions $[1,2]$.

\section{STRUCTURE AND ROLE OF VASCULAR ENDOTHELIAL GLYCOCALYX UNDER PHYSIOLOGICAL CONDITIONS}

The endothelial surface on the lumen side is lined with glycocalyx, which is a gel layer made by a network of proteoglycans and glycoproteins as well as adsorbed plasma proteins. The thickness of the glycocalyx depends on the type and calibre of the vessel. In the capillaries, it is about $0.2-0.5 \mu \mathrm{m}$ [3], while in arterial vessels it ranges 
from $2-3 \mu \mathrm{m}$ in small arterioles [4] to $4.5 \mu \mathrm{m}$ in the carotid artery [5]. The proteoglycans consist of a protein core to which glycosaminoglycan (GAG) chains are attached. The protein core may be linked to endothelial membrane (syndecan, glypican). Other proteoglycans like perlecan, versican, decorin, biglycan and mimecan, after complete intracellular synthesis, are secreted out of the cell and may remain in the glycocalyx or be dissolved in the plasma. There are five types of GAGs: The heparin sulfate (HS), dermatan sulfate (DS), keratan sulfate, chondroitin sulfate and hyaluronan (or hyaluronic acid). All of them are linear polymers of disaccharides with different lengths, which are modified by sulfation and/or (de) acetylation. The HS represents about $50-90 \%$ of the total amount of GAGs present in the glycocalyx. The second most common GAG in the glycocalyx is DS, the typical proportion between HS and DS is $4: 1$ in the vascular endothelium [6]. The content of GAGs in proteoglycans may change under different conditions. The presence of the sulfate groups gives a negative charge, which prevents the adhesion of platelets and leukocytes in physiological conditions to the endothelial surface [7]. It has been demonstrated that the degradation of the heparan sulfate chains by heparanase leads to an increase of leukocyte adhesion to endothelial cells [8]. The glycocalyx which is located between the stream of blood and endothelium is an important determinant of vascular permeability because it restricts the access of negatively charged plasma proteins to the endothelial cell membrane. Hence, glycocalyx degradation leads to a significant increase in vascular permeability [3].

The glycocalyx participates in the mechano-transduction of the shear stresses exerted by the flowing blood stream. It was observed that under the influence of heparanase and hyaluronidase, the endothelial secretion of NO in response to shear stress is impaired. Thus, both the HS as well as the hyaluronan seem to play an important role in the detection and amplification of flow-induced shear forces $[9,10]$. Moreover, numerous growth factors, like the fibroblast growth factor (FGF) and FGF-4 [11], enzymes like lipoprotein lipase (LPL) [12], and chemokines are bound to the surface of endothelium via glycosaminoglycans. The GAGs immobilize them, increase their local concentration and protect them from degradation. This allows for proper signal transduction or enzymatic modification.

Another important aspect is the role of the glycocalyx in anticoagulant barriers, especially in small vessels [13]. The HS has an affinity for antithrombin III (AT) and increases its activity by about 1000 times, probably by stabilizing the active site. The AT is an inhibitor mostly of alpha-thrombin, factor Xa (FXa) and factor IXa (FIXa), and to a lesser extent factor VIIa (FVIIa) in combination with tissue factor (TF) [13]. Secondary important in the inactivation of alpha-thrombin is the heparin cofactor II (HCII) which is activated by DS [14]. Moreover, HS is directly involved in the uptake and degradation of the complexes of TFPI-FXa [15].

The endothelial glycocalyx also modulates the inflammatory response by binding cytokines and decreasing interaction with cell receptors. Decreasing the content of HS in the glycocalyx increases the sensitivity of endothelial cells on activation by cytokines [16]. Furthermore, the glycocalyx has the ability to bind antioxidants, like extracellular superoxide dismutase (EC-SOD), which reduces the exposure of endothelial cells to oxidative stress [17].

\section{THE ROLE OF VASCULAR ENDOTHELIAL GLYCOCALYX IN PATHOLOGICAL CONDITIONS}

Recently, there is an increasing amount of evidence that damage to the endothelial glycocalyx plays a key role in the pathology of many vascular diseases. The impact of diabetes mellitus (DM), ischaemia, reperfusion and associated consequences like atherosclerosis on the endothelial glycocalyx, has been extensively researched.

Hyperglycaemia associated with DM correlates with microvascular distributions. It is manifested initially as increased permeability [18] and abnormal function of NO synthase [19], which can be the effect of the depletion of glycocalyx. During progression of the disease, albuminuria occurs due to loss of the GAGs in the glomerular basement membrane [20]. In an interesting experiment, in a group of healthy volunteers, after 6 hours of acute hyperglycaemia, Nieuwdorp et al. [21] observed that the total volume of the systemic glycocalyx was reduced by almost half with concomitant activation of the coagulation system and an increase in the hyaluronan level in the blood. The same group of researchers found that among patients with type I diabetes, there is also a reduction in the systemic glycocalyx volume by about $50 \%$, and in patients with type I DM and microalbuminuria, the systemic volume of glycocalyx is even smaller [22]. In addition, it was observed that cells damaged in the process of glycosylation, with a thinner layer of glycocalyx, showed a tendency to increase adhesion of neutrophils [23]. Ischaemia and subsequent reperfusion are responsible for free radical reactions leading to severe damage of the endothelium. Endothelial cells become swollen and detached from the basement membrane [24], increase permeability of the vessel wall [25] as well as adhesion and transmigration of leukocytes [26]. The greatest damage occurs inside the post-capillary venules [27]. The role of glycocalyx in this process has been studied both in experimental studies on animals [28] and patients after major vascular surgery [29], or cardiac arrest [30]. It was observed that after the return of circulation there is a significant increase in sydecan-1 and HS level in the blood, associated with a thinning of the endothelial glycocalyx layer. In addition, after cardiac arrest concentrations of both syndecan-1 and HS were higher among patients who died [30]. However, the administration of exogenous 
hyaluronan or pertussis toxin which inhibits the activity of enzymes responsible for the cleavage of GAGs chains, reduces ischaemia and reperfusion injury of the endothelium [28].

The endothelial glycocalyx can be treated as a first line of defence against the development of atherosclerosis. It turns out that a pro-atherogenic diet can cause thinning of the endothelial glycocalyx layer, as was demonstrated in a study conducted on rats [31]. The reduction in negative charge on the surface of the endothelium results in facilitating the interaction of platelets with endothelial cells [32]. Moreover, the elution of NO in response to shear stress is reduced [9]. The endothelial defence against exposure to free radicals becomes impaired [33]. Consequently, an increase in intensity of the inflammatory process in the vessel wall and the subsequent development of atherosclerotic lesions is observed.

\section{SULODEXIDE (SDX)}

Sulodexide is a highly purified mixture of GAGs consisting of $80 \%$ fast-moving heparin (FMH) and $20 \%$ DS. It is a unique derivative of heparin, which can be administered both parenterally and orally. Owing to a low molecular weight, both fractions of SDX are absorbed over the entire length of the gastrointestinal tract. In comparison to unfractionated heparin (UFH) which contains chains from 3,000 to 30,000 Da, FMH has a molecular weight of only about 7,000 Da. The FMH is different from UFH not only in the molecular weight but also because of a smaller number of sulfate groups and a reduced anticoagulant activity. Independently from the method of administration, one of the most important targets for SDX are the vascular endothelial cells. After intravenous administration an influence of SDX on the coagulation system is expressed more, while after oral administration a stronger pleiotropic effect of the drug can be observed.

\section{THE INFLUENCE OF SDX ON THE COAGULATION SYSTEM}

The FMH has an affinity for AT, as opposed to that of DS which has an affinity for heparin cofactor II (HCII). This implies an anticoagulant activity of SDX proportional to the dose administered $[34,35]$. What is more important, the anticoagulant activity of SDX is stronger than that of the individual FMH and DS [36]. Compared to heparin, SDX has a longer half-life and has less impact on vascular haemostasis and a lower risk of inducing bleeding [37]. Furthermore, SDX administered intravenously strongly stimulates the release of TFPI from endothelial cells $[38,39]$. However, on the other hand long-term use of oral SDX can lead to depleted resources of this inhibitor in endothelium and decrease its concentration in the blood. The SDX also exhibits a pro-fibrinolytic activity. It reduces fibrinogen content in the blood by increasing
tPA activity and decreasing PAI activity [40]. Moreover, it was observed that SDX binds to preformed fibrin and stimulates local thrombolysis [41]. On the other hand, it reduces platelet aggregation by decreasing the concentration of pro-aggregatory factors like thrombin, cathepsin G or elastase [42].

\section{PROTECTIVE AND REPARATIVE INFLUENCE OF SDX ON VASCULAR ENDOTHELIAL CELLS}

The protective effect of SDX on vascular endothelial glycocalyx comes not only from the delivery of substrates to rebuild, but also due to inhibition of the enzyme activity which degrades the GAGs. It has been demonstrated that SDX is a heparanase- 1 inhibitor [43]. At the same time, in a group of patients with type II DM it was observed that SDX decreased the hyaluronidase level in plasma and increased the glycocalyx dimensions [44]. Moreover, SDX stimulates the restoration of the damaged vessel wall by increasing the activity of growth factors involved in repairing, and among other things increases the release of the hepatocyte growth factor (HGF) [45] or stabilizes fibroblast growth factors (FGFs) [46]. At the same time SDX is responsible for the inhibition of growth factors with pro-angiogenic and profibrinolytic activity by binding vascular endothelial growth factor (VEGF) [47] or transforming growth factor- $\beta 1$ (TGF- $\beta 1$ ), which are involved in proliferation of vascular wall cells [48].

Borawski et al. conducted a series of interesting experiments on healthy volunteers to investigate the influence of SDX on endothelial cells. In one study, SDX significantly increased HGF levels in the blood after intravenous administration, but there was no similar effect after oral route administration [45]. In another study, the same researchers found that oral administration of SDX leads to a reduction in the level of TGF- $\beta 1$ in the blood by $50 \%$ after just 2 weeks of treatment, possibly due to a decreased expression of this protein [48].

A completely different beneficial aspect of the protective effects of SDX is protection against glucose toxicity [49]. In an experiment performed on in vitro cultured human umbilical vein endothelial cells (HUVECs), Sumińska-Jasińska [50] demonstrated that SDX, proportional to a dose-dependent manner, inhibits the generation of free radicals, and releases monocyte chemotactic protein 1 (MCP-1) and IL-6. Furthermore, SDX prevents impairment of the ability of the endothelium to heal itself in hyperglycaemic conditions and slows down morphological and functional changes in endothelial cells caused by their aging process.

\section{ANTI-INFLAMMATORY INFLUENCE OF SDX ON VASCULAR ENDOTHELIAL CELLS}

As mentioned above, SDX has anti-inflammatory effects on the endothelium. Through restoration of the 
glycocalyx, SDX reduces leukocyte adhesion and reduces the proteolytic activity of leukocytes by the inhibition of matrix metalloproteinases (MMPs). It has been also shown that SDX reduces the secretion of matrix metalloproteinase-9 (MMP-9) without affecting the level of matrix metalloproteinase-2 (MMP-2). It should be noted that the FMH itself does not inhibit the expression of MMP-9, so this effect is associated with the DS or an interaction with FMH-DS [51]. The MMP-9 and MMP-2 play an important role in vascular pathology because they increase endothelial permeability due to a degradation of the extracellular matrix and the glycocalyx, as well as promote apoptosis [52]. Moreover, SDX has significant influence on the pro-inflammatory cytokine profile released by macrophages. Proportional to a dose-dependent manner, it reduces the release of IL- $1 \beta$, IL-7, IL-8, IL-12, IL-17, granulocyte colony-stimulating factor (G-CSF) as well granulocyte-macrophage colony-stimulating factor (GM-CSF), MCP-1, macrophage inflammatory protein-1 $\alpha$ (MIP-1 $\alpha)$ and TNF- $\alpha$. However, independently of the dose it reduces INF- $\gamma$, IL-4, IL-6, IL-10, IL-12 and IL-13 [53]. The SDX decreases the level of pro-inflammatory cytokines and chemokines without significantly affecting the level of anti-inflammatory interleukins. Lauver et al. [54], in an experiment conducted on an animal model observed that intravenous administration of SDX after 30 min of coronary artery occlusion was associated with a reduction of almost half the myocardial infarct size and a significantly lowered increase in the level of troponin I, with no significant effect on the coagulation system. The authors postulate that the cardioprotective effect of SDX during reperfusion may result from its ability to stabilize the cell membranes of cardiomyocytes, by inhibiting the activation of the complement system. Moreover, they argue that the SDX contributed to a marked reduction in $\mathrm{C}$ reactive protein (CRP) deposits as well as membrane-attacking complex (MAC) in the area of the damaged myocardium. It should also be remembered that the CRP protein belongs to a strong activator of the complement system [54].

\section{ANTIOXIDANT AND ANTI-APOPTOTIC EFFECT}

Endothelial cells destruction through reactive oxygen species (ROS) plays a crucial role in the pathogenesis of ischaemia-reperfusion tissue damage. Based on a series of experiments performed by Gabryel et al. [55] on human umbilical vein endothelial cells (HUVEC) line, it was shown that SDX increases the expression of superoxide dismutase 1 (SOD1) and glutathione peroxidase 1 (GPx1) in conditions of oxygen and glucose deprivation (OGD), which simulate ischaemia. The SOD catalyzes the dismutation of superoxide anion in the reaction:

$$
2 \mathrm{O}_{2}^{-}+2 \mathrm{H}^{+} \leftrightarrow \mathrm{O}_{2}+\mathrm{H}_{2} \mathrm{O}_{2} .
$$

In the human system there exist three isoforms of SOD: cytoplasmic SOD1 containing copper $(\mathrm{Cu})$ and zinc (Zn) CuZnSOD-1, mitochondrial SOD2 containing manganese (Mn) MnSOD-2 and SOD3 (or EC SOD) containing copper and zinc CuZnSOD-3 - which is secreted outside the cell. It is thought that SOD is the first line of defence against ROS. The resulting hydrogen peroxide $(\mathrm{H} 2 \mathrm{O} 2)$ is subsequently decomposed by catalase (CAT) or GPx. The CAT localized in peroxisomes is responsible for the conversion of hydrogen peroxide to water and molecular oxygen:

$$
2 \mathrm{H}_{2} \mathrm{O}_{2} \leftrightarrow \mathrm{O}_{2}+2 \mathrm{H}_{2} \mathrm{O}
$$

It was demonstrated that SDX does not increase CAT expression in the HUVECs exposed to OGD [55]. While GPx, which is a selenoperoxidase with the participation of glutathione $(\mathrm{GSH})$, reduces both hydrogen peroxide:

$$
2 \mathrm{GSH}+\mathrm{H}_{2} \mathrm{O}_{2}^{\mathrm{GPX}} \rightarrow \mathrm{GS}-\mathrm{SG}+2 \mathrm{H}_{2} \mathrm{O},
$$

as well as organic peroxides $(\mathrm{ROOH})$ to hydroxy acids (ROH):

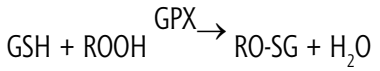

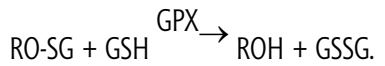

Due to reduction of lipidic and non-lipid hydroperoxides, GPx is the main source of protection in conditions with a low level of oxidant stress [56]. Among several isoforms of this enzyme in human vascular endothelial cells, the GPx1 dominates [57]. Depletion of antioxidant defence during ischaemia contributes to lipid peroxidation intensification, loss of cell membrane integrity and subsequent cell death. Moreover, ROS directly damages the mitochondria and is responsible for disturbances of their functions. During ischaemia, a mitochondrial swelling is observed associated with mitochondrial permeability transition pore (MPTP) opening, which results in an uncoupling of the respiratory chain and oxidative phosphorylation impairment. The MPTP directly initiates apoptosis by increasing the release of cytochrome c into the cytosol. In cytoplasm, cytochrome $\mathrm{c}$ binds to apoptotic protease activating factor-1 (Apaf-1), which in the presence of ATP activates procaspase 9. Procaspase 9 activates the caspase cascade and inevitably leads to programmed cell death [58]. In an experiment conducted on ischaemic HUVECs, SDX inhibited apoptosis [55]. It seems that low molecular weight heparins (LMWHs) can be chiefly responsible for the anti-apoptotic effect, which, as a strong polyanion, has an affinity for the positively charged cytochrome c [59]. Gabryel et al. [55] observed that SDX reduces release of cytochrome $c$ into the cytoplasm and inhibits the mitochondrial pathway of programmed death. Among the growing number of reports which suggest that LMWH inhibits the activity of nuclear factor kappa-light-chain-enhancer of activated $B$ cells $(N F-\kappa B)$, it seems that ischaemia-induced NF- $\kappa B$ 
activation may play a key role in regulating the expression of SOD1 and GPx1. One hypothesis assumes that polyanionic LMWH competes with the NF- $\kappa \mathrm{B}$ in binding with corresponding domains in DNA [60]. While another says that LMWH interferes with phosphorylation of NF- $\kappa \mathrm{B}$, thereby preventing this binding to DNA. It appears that the inhibition of NF- $\kappa$ B by LMWH may be an important link between the activation of the antioxidant enzymes and the inhibition of apoptosis in the protective action of SDX on the vascular endothelial cells under ischemic conditions.

\section{ANTIATHEROSCLEROTIC EFFECT}

Basically, any of the above aspects of the impact of SDX on endothelium can be considered as modulating effects which lead to the development of an atherosclerotic plaque. Of course, of paramount importance are the anti-inflammatory, antioxidant and endothelioprotective effects.

Thinning of the endothelial glycocalyx layer increases endothelial permeability for lipoproteins, monocytes and other atherogenic particles from the blood stream. That is why reconstruction of the glycocalyx by SDX is one mechanism of this anti-atherogenic activity [61]. Equally significant seems to be the antiproliferative activity of SDX relative to the smooth muscle cells and fibroblasts [62], which was confirmed on an animal model in vivo [63]. Furthermore, numerous experiments have shown that SDX decreases the release of MCP-1 by monocytes. The MCP-1 protein is responsible for the transmigration of monocytes into the subendothelial layer where they transform into macrophages, and then through uncontrolled phagocytosis of oxy-LDL into foam cells, which are pathognomonic of atherosclerotic lesions $[49,64]$. It should be noted that SDX reduces the levels of MMPs, which also increase the migration of smooth muscle cells and stimulate angiogenesis as well as pathological remodelling of the vascular wall [52]. Moreover, SDX has beneficial effects on lipid profiles by increasing lipoprotein lipase activity in endothelial cells [65].

In a series of experiments conducted on HUVEC cell lines in OGD conditions, it was confirmed that SDX inhibits endothelial nitric oxide synthase uncoupling (eNOS) [55]. Probably this effect may be associated with increased activity of SOD1 and GPx1. Indeed, there are reports that a deficiency of SOD1 and GPx1 promote the uncoupling of eNOS $[66,67]$. Furthermore, SDX increased in a dose dependent manner the expression of eNOS during ischaemia. A possible cause may be the inhibition of kinase $\mathrm{C}$ by $\mathrm{LMWH}$, and consequently reducing phosphorylation of eNOS at Thr495 [68]. The NO plays not only a key role in the process of regulating the tension of the vascular wall, but is also a determinant of normal endothelial function.
The way SDX influences the biology of vascular endothelial cells is not completely understood. Regardless of this, impact on endothelial glycocalyx, localized on the surface of cells, demonstrates influence on the expression of multiple growth factors [45-47]. It penetrates inside a cell, where it binds to transcription factors and induces a phenotypic change of endothelium $[55,60,68]$. Consequently, it shows protective and reparative effects as well as reduces intensification of inflammation and free radical reactions. Moreover, it has antiproliferative, anti-apoptotic and anti-atherosclerotic properties. Therefore, the multimodal influence on the endothelium makes SDX a drug with enormous therapeutic potential in the treatment of many vascular diseases. It has proven effects in the treatment of disorders which are the result of longterm diabetes, including diabetic nephropathy $[44,69]$. Furthermore, it is suitable for the treatment of peripheral vascular diseases. Its beneficial effect is documented in the treatment of chronic venous insufficiency (CVI) [70] and peripheral artery disease (PAD) [71].

\section{CHRONIC VENOUS DISEASE AND CHRONIC VENOUS INSUFFICIENCY}

Chronic venous disease (CVD) is a very common pathology related to vascular endothelium dysfunction. Beebe-Dimmer et al. [72] noticed that in Western countries, reports about the prevalence of CVD are very diverse and indicate that from $<1 \%$ to $40 \%$ of women and $<1 \%$ to $17 \%$ of men suffer from chronic venous insufficiency (CVI). The estimated frequency of varicose veins is higher and ranges from $<1 \%$ to $73 \%$ in women and from $2 \%$ to $56 \%$ in men. These wide ranges presumably represent differences in the accuracy of diagnostic criteria, risk factors, as well as the quality and availability of diagnostic resources [72]. According to a Polish study, CVD occurs in $47 \%$ of women and $37 \%$ of men [73].

The CVD, regardless of aetiology, is the consequence of impaired blood flow resulting from structural or functional abnormalities of the venous wall and valves. As a result of congenital or acquired damage of the venous valves, reflux and retention of the blood in the lower leg venous system is observed. In addition to primary venous valve/wall lesions, incompetence of the venous system can also occur from other reasons, such as deep or superficial venous thrombosis and post-thrombotic syndrome. In patients with venous incompetence, venous hypertension is transferred from the large vessels into the capillaries and finally into the microcirculation [74].

As a result of abnormal rheological conditions, shear stress disturbances as well as venous hypertension and dysfunction of the vascular endothelium develop. As a consequence, endothelial cell activation with depletion of the glycocalyx layer increases capillary permeability leading to development of local oedema and migration of the activated leukocytes into the perivascular space. All 
this leads to an inflammatory reaction in both the lumen and vessel wall, as well as in the extravascular space. Transudate fluid contains fibrinogen, which polymerizes in the extravascular space and forms fibrin deposits around the capillaries [75]. These so called "fibrin perivascular cuffs" also hinder the distribution of oxygen to the surrounding tissues. The oxygen insufficiency as well as white cells activation increase free radical production, which aggravates cell damage. This leads to changes in the phenotype of the endothelial cells, further leukocyte activation as well as stimulates the production of numerous growth factors and pro-inflammatory cytokines. The endothelial glycocalyx which in these conditions has been significantly depleted also increases the expression of adhesion molecules taking part in further inflammatory reaction activation [76]. Additionally, the presence of red blood cells in the perivascular transudate is also not insignificant. Red blood cells undergoing extravascular lysis become a rich source of haemoglobin and haemosiderin, proteins with potent chemotactic properties. Another important process is the significant increase in the metaloproteinases (MMPs) activity leading to increased degradation of the extracellular matrix and venous wall structure degeneration [77]. Changes also occur in the skin and subcutaneous tissue; stimulated fibroblasts as well as inflammatory reaction cause fibrosis as well as chronic inflammatory changes in the skin and subcutaneous tissues. Activation of inflammatory processes that lead to increased blood viscosity and flow disturbances predispose also to thrombosis [76].

The clinical presentation of CVD depends on the stage of the disease. It is described by a series of classifications; one example that is widely used is the CEAP (clinical, etiology, anatomy, and pathophysiology) classification.

\section{SULODEXIDE IN THE TREATMENT OF CHRONIC VENOUS INSUFFICIENCY - CLINICAL TRIALS [77]}

The main therapeutic target in the treatment of CVD is the reduction of venous hypertension, by improving calf muscle pump, by compression therapy and surgical or endovascular interventions as the means to eliminate the reflux sources [78]. In addition, pharmacotherapy in the treatment of CVD is implemented as the sole or adjuvant measure. Regarding pharmacotherapy, priority is given to symptomatic patients with CVD whether with oedema or leg ulceration, often in combination with other methods of treatment [79]. Nowadays, many of the molecules belonging to the group of the so called phlebotropic agents act on the vascular endothelium function and homeostasis. In this context the potential multimodal activity of SDX in CVD should be emphasized. The positive effect, anti-inflammatory, MMP production inhibition, free radical generation decrease and endothelial cell protection, of SDX administration documented in the in vitro studies concerning CVD has also be confirmed clinically [53, 55, 64]. In 1992, Cospite et al. [80, 81] reported the results of two double-blind, placebo-controlled studies conducted on small groups of patients suffering from varicose veins and symptoms of post-thrombotic syndrome. The researchers observed the beneficial effects of SDX on blood flow parameters assessed by strain gauge plethysmography and continuous wave (CW) Doppler in the veins of the lower limbs. Moreover, SDX relieved symptoms like pain, pruritus, oedema and paraesthesia. In another study, conducted on 476 patients with primary or secondary CVD, the effectiveness of SDX in reducing the symptoms and decreasing elevated venous pressure was confirmed [70].

In 2002, the results of a multi-centre clinical trial the Sulodexide Arterial Venous Italian Study (SUAVIS) conducted on a group of 235 patients with leg ulcers (230 patients with venous leg ulcers) were published. Patients undergoing wound care and compression therapy were randomised to SDX or placebo. Better results were achieved in the treatment of ulcers among patients who, in addition to compression therapy and local treatment, were given SDX. After two months of treatment, a complete healing of ulcers was achieved in $35 \%$ of patients treated with SDX and in $21 \%$ of those receiving placebo; after three months healing was $53 \%$ and $33 \%$ respectively. Furthermore, the same study found a significant reduction in the level of plasma fibrinogen also [82]. Similar results were also obtained by other researchers [83-85]. As a result, SDX appeared in the recommendations of the American College of Chest Physicians (ACCP) evidence-based clinical practice guidelines ( $8^{\text {th }}$ Edition) as an adjuvant systemic treatment of venous ulcers [86].

At the end of 2015, Andreozzi et al. [87] presented the results of a multi-centre clinical study on a group of 615 patients; the Sulodexide in secondary prevention of recurrent deep vein thrombosis (SURVET). The study included patients with a first, unprovoked venous thromboembolism (VTE) episode, after 3 to 12 months of anticoagulant therapy and application of compression stockings. Patients were randomly allocated to one of two groups: the first group after completing oral anticoagulant treatment with vitamin $\mathrm{K}$ antagonists received twice daily 500 lipasaemic units (LRU) of SDX for 2 years and the second group received a placebo. In addition, patients used graduated elastic compression stockings class II. Recurrence of VTE occurred in 15 of the 307 patients who received SDX and in 30 of the 308 patients who received placebo. Bleeding episodes were noted in 2 patients in each group. Also, the incidence of other side effects did not differ significantly between these two methods of treatment. Based on these results, it can be assumed that SDX administered after discontinuation of anticoagulant therapy reduces the risk of recurrence of venous thrombosis with no apparent increased risk of bleeding [87]. 


\section{CONCLUSIONS}

Considering the pleiotropic action of SDX documented in several in vitro and in vivo studies, this drug can potentially support the effective treatment of CVD. Treatment of endothelial dysfunction does not eliminate the primary cause of CVD, which is venous hypertension as a result of damage to the valves and the wall of the veins. In light of the above studies, administration of SDX seems to be important in suppressing the local inflammatory reaction, expression of metalloproteinases and in the protection of vascular endothelium. Further studies are required to add more in-depth knowledge of the potential impact of GAGs (i.e. SDX), both in the course as well as in the treatment of CVD in various stages and clinical scenarios.

\section{ACKNOWLEDGMENT}

This work was supported by a statutory grant from Silesian Medical University in Katowice No KNW-1$116 / \mathrm{N} / 5 / 0$.

The authors declare no conflict of interest.

\section{References}

1. Undas A., Ariëns R.A. Fibrin clot structure and function: a role in the pathophysiology of arterial and venous thromboembolic diseases. Arterioscler Thromb Vasc Biol 2011; 31: 88-99.

2. Aird W.C. Endothelium and haemostasis. Hamostaseologie 2015; 35: 11-16.

3. van den Berg B.M., Vink H., Spaan JA. The endothelial glycocalyx protects against myocardial edema. Circ Res 2003; 92: 592594.

4. van Haaren P.M., VanBavel E., Vink H., Spaan J.A. Localization of the permeability barrier to solutes in isolated arteries by confocal microscopy. Am J Physiol Heart Circ Physiol 2003; 285: 2848-2856.

5. Megens R.T., Reitsma S., Schiffers P.H., Hilgers R.H., De Mey J.G., Slaaf D.W., oude Egbrink M.G., van Zandvoort M.A. Two-photon microscopy of vital murine elastic and muscular arteries. Combined structural and functional imaging with subcellular resolution. J Vasc Res 2007; 44: 87-98.

6. Rapraeger A., Jalkanen M., Endo E., Koda J., Bernfield M. The cell surface proteoglycan from mouse mammary epithelial cells bears chondroitin sulfate and heparan sulfate glycosaminoglycans. J Biol Chem 1985; 260: 11046-11052.

7. Reitsma S., Slaaf D.W., Vink H., van Zandvoort M.A. The endothelial glycocalyx: composition, functions, and visualization. Pflugers Arch 2007; 454: 345-359.

8. Constantinescu A.A., Vink H., Spaan J.A. Endothelial cell glycocalyx modulates immobilization of leukocytes at the endothelial surface. Arterioscler Thromb Vasc Biol 2003; 23: 1541-1547.

9. Mochizuki S., Vink H., Hiramatsu O., Kajita T., Shigeto F., Spaan J.A., Kajiya F. Role of hyaluronic acid glycosaminoglycans in shear-induced endothelium-derived nitric oxide release. Am J Physiol Heart Circ Physiol 2003; 285: 722-726.
10. Florian J.A., Kosky J.R., Ainslie K., Pang Z., Dull R.O., Tarbell J.M. Heparan sulfate proteoglycan is a mechanosensor on endothelial cells. Circ Res 2003; 93: 136-142.

11. Allen B.L., Filla M.S., Rapraeger A.C. Role of heparan sulfate as a tissue-specific regulator of FGF-4 and FGF receptor recognition. J Cell Biol 2001; 155: 845-858.

12. Wilsie L.C., Orlando R.A. The low density lipoprotein receptor-related protein complexes with cell surface heparan sulfate proteoglycans to regulate proteoglycan-mediated lipoprotein catabolism. J Biol Chem 2003; 278: 15758-15764.

13. Shimada K., Kobayashi M., Kimura S., Nishinaga M., Takeuchi K., Ozawa T. Anticoagulant heparin-like glycosaminoglycans on endothelial cell surface. Jpn Circ J 1991; 55: 1016-1021.

14. Tollefsen D.M., Pestka C.A. Heparin cofactor II activity in patients with disseminated intravascular coagulation and hepatic failure. Blood 1985: 66: 769-774.

15. Ho G., Broze G.J. Jr, Schwartz A.L. Role of heparan sulfate proteoglycans in the uptake and degradation of tissue factor pathway inhibitor-coagulation factor Xa complexes. J Biol Chem 1997; 272: 16838-16844.

16. Bode L., Murch S., Freeze H.H. Heparan sulfate plays a central role in a dynamic in vitro model of protein-losing enteropathy. J Biol Chem 2006; 281: 7809-7815.

17. Maksimenko AV, Vavaev AV. Antioxidant enzymes as potential targets in cardioprotection and treatment of cardiovascular diseases. Enzyme antioxidants: the next stage of pharmacological counterwork to the oxidative stress. Heart Int 2012; 7: e3.

18. Algenstaedt P., Schaefer C., Biermann T., Hamann A., Schwarzloh B., Greten H., Ruther W., Hansen-Algenstaedt N. Microvascular alterations in diabetic mice correlate with level of hyperglycemia. Diabetes 2003; 52: 542-549.

19. Du XL., Edelstein D., Dimmeler S., Ju Q., Sui C., Brownlee M. Hyperglycemia inhibits endothelial nitric oxide synthase activity by posttranslational modification at the Akt site. J Clin Invest 2001; 108: 1341-1348.

20. Torffvit O. Urinary sulphated glycosaminoglycans and Tamm-Horsfall protein in type 1 diabetic patients. Scand J Urol Nephrol 1999; 33: 328-332.

21. Nieuwdorp M., van Haeften T.W., Gouverneur M.C., Mooij H.L., van Lieshout M.H., Levi M., Meijers J.C., Holleman F., Hoekstra J.B., Vink H., Kastelein J.J., Stroes E.S. Loss of endothelial glycocalyx during acute hyperglycemia coincides with endothelial dysfunction and coagulation activation in vivo. Diabetes. 2006; 55: 480-486.

22. Nieuwdorp M., Mooij H.L., Kroon J., Atasever B., Spaan J.A., Ince C., Holleman F., Diamant M., Heine R.J., Hoekstra J.B., Kastelein J.J., Stroes E.S., Vink H. Endothelial glycocalyx damage coincides with microalbuminuria in type 1 diabetes. Diabetes. 2006; 55: 1127-1132.

23. Patel K.D., Nollert M.U., McEver R.P. P-selectin must extend a sufficient length from the plasma membrane to mediate rolling of neutrophils. J Cell Biol 1995; 131: 1893-1902.

24. Oliver M.G., Specian R.D., Perry M.A., Granger D.N. Morphologic assessment of leukocyte-endothelial cell interactions in mesenteric venules subjected to ischemia and reperfusion. Inflammation 1991; 15: 331-346.

25. Kupinski A.M., Shah D.M., Bell D.R. Transvascular albumin flux in rabbit hindlimb after tourniquet ischemia. Am J Physiol 1993; 264: 901-908.

26. Beuk R.J., Heineman E., Tangelder G.J., Quaedackers J.S., Marks W.H, Lieberman J.M., oude Egbrink M.G. Total warm ischemia 
and reperfusion impairs flow in all rat gut layers but increases leukocyte-vessel wall interactions in the submucosa only. Ann Surg 2000; 231: 96-104.

27. Kurose I., Argenbright L.W., Wolf R., Lianxi L., Granger D.N. Ischemia/reperfusion-induced microvascular dysfunction: role of oxidants and lipid mediators. Am J Physiol 1997; 272: 29762982.

28. Mulivor A.W., Lipowsky H.H. Inflammation- and ischemia-induced shedding of venular glycocalyx. Am J Physiol Heart Circ Physiol 2004; 286: 1672-1680.

29. Rehm M., Bruegger D., Christ F., Conzen P., Thiel M., Jacob M., Chappell D., Stoeckelhuber M., Welsch U., Reichart B., Peter K., Becker BF. Shedding of the endothelial glycocalyx in patients undergoing major vascular surgery with global and regional ischemia. Circulation 2007; 116: 1896-1906.

30. Grundmann S., Fink K., Rabadzhieva L., Bourgeois N., Schwab T., Moser M., Bode C., Busch H.J. Perturbation of the endothelial glycocalyx in post cardiac arrest syndrome. Resuscitation 2012; 83: 715-720.

31. van den Berg B.M., Spaan J.A., Rolf T.M., Vink H. Atherogenic region and diet diminish glycocalyx dimension and increase intima-to-media ratios at murine carotid artery bifurcation. Am J Physiol Heart Circ Physiol 2006; 290: 915-920.

32. Reitsma S., Oude Egbrink M.G., Heijnen V.V., Megens R.T., Engels W., Vink H., Slaaf D.W., van Zandvoort M.A. Endothelial glycocalyx thickness and platelet-vessel wall interactions during atherogenesis. Thromb Haemost 2011; 106: 939-946.

33. Vink H., Constantinescu A.A., Spaan J.A. Oxidized lipoproteins degrade the endothelial surface layer: implications for plateletendothelial cell adhesion. Circulation 2000; 101: 1500-1502.

34. Harenberg J. Review of pharmacodynamics, pharmacokinetics, and therapeutic properties of sulodexide. Med Res Rev 1998; 18: 1-20.

35. Ofosu F.A. Pharmacological actions of sulodexide. Semin Thromb Hemost 1998; 24: 127-138.

36. Cosmi B., Cini M., Legnani C., Pancani C., Calanni F., Coccheri S. Additive thrombin inhibition by fast moving heparin and dermatan sulfate explains the anticoagulant effect of sulodexide, a natural mixture of glycosaminoglycans. Thromb Res 2003; 109: 333-339.

37. Andreozzi G.M. Sulodexide in the treatment of chronic venous disease. Am J Cardiovasc Drugs 2012; 12: 73-81.

38. Borawski J., Naumnik B., Dubowski M., Mysliwiec M. Fulllength TFPI release by heparinoid sulodexide. Clin Appl Thromb Hemost 2010; 16: 485-487.

39. Borawski J., Gozdzikiewicz J., Dubowski M., Pawlak K., Mysliwiec M. Tissue factor pathway inhibitor release and depletion by sulodexide in humans. Adv Med Sci 2009; 54: 32-36.

40. Crepaldi G., Rossi A., Coscetti G., Abbruzzese E., Calveri U., Calabrò A. Sulodexide oral administration influences blood viscosity and fibrinolysis. Drugs Exp Clin Res 1992; 18: 189-195.

41. Barbanti M., Guizzardi S., Calanni F., Marchi E., Babbini M. Antithrombotic and thrombolytic activity of sulodexide in rats. Int J Clin Lab Res 1992; 22: 179-184.

42. Rajtar G., Marchi E., de Gaetano G., Cerletti C. Effects of glycosaminoglycans on platelet and leucocyte function: role of N-sulfation. Biochem Pharmacol 1993; 46: 958-960.

43. Masola V., Onisto M., Zaza G., Lupo A., Gambaro G. A new mechanism of action of sulodexide in diabetic nephropathy: inhibits heparanase-1 and prevents FGF-2-induced renal epithelial-mesenchymal transition. J Transl Med 2012; 10: 213.
44. Broekhuizen L.N., Lemkes B.A., Mooij H.L., Meuwese M.C., Verberne H., Holleman F., Schlingemann R.O., Nieuwdorp M., Stroes E.S., Vink H. Effect of sulodexide on endothelial glycocalyx and vascular permeability in patients with type 2 diabetes mellitus. Diabetologia 2010; 53: 2646-2655.

45. Borawski J., Dubowski M., Pawlak K., Mysliwiec M. Sulodexide induces hepatocyte growth factor release in humans. Eur J Pharmacol 2007; 558: 167-171.

46. Tardieu M., Bourin MC., Desgranges P., Barbier P., Barritault D., Caruelle J.P. Mesoglycan and sulodexide act as stabilizers and protectors of fibroblast growth factors (FGFs). Growth Factors 1994; 11: 291-300.

47. Pletinck A., Van Landschoot M., Steppan S., Laukens D., Passlick-Deetjen J., Vanholder R., Van Biesen W. Oral supplementation with sulodexide inhibits neo-angiogenesis in a rat model of peritoneal perfusion. Nephrol Dial Transplant 2012; 27: 548-556.

48. Borawski J., Dubowski M., Pawlak K., Mysliwiec M. Effect of sulodexide on plasma transforming growth factor-betal in healthy volunteers. Clin Appl Thromb Hemost 2010; 16: 60-65.

49. Ciszewicz M., Polubinska A., Antoniewicz A. Suminska-Jasinska K., Breborowicz A. Sulodexide suppresses inflammation in human endothelial cells and prevents glucose cytotoxicity. Transl Res 2009; 153: 118-123.

50. Suminska-Jasinska K. Assessment of sulodexide influence on function human endothelial cells in vitro. PhD Thesis. 2012; Department of Pathophysiology, Poznan University of Medical Sciences, Poznan, Poland.

51. Mannello F., Medda V., Ligi D., Raffetto J.D. Glycosaminoglycan sulodexide inhibition of MMP-9 gelatinase secretion and activity: possible pharmacological role against collagen degradation in vascular chronic diseases. Curr Vasc Pharmacol 2013; 11: 354-365.

52. Raffetto J.D., Khalil R.A. Matrix metalloproteinases in venous tissue remodeling and varicose vein formation. Curr Vasc Pharmacol 2008; 6: 158-172.

53. Mannello F., Ligi D., Canale M., Raffetto J.D. Sulodexide down-regulates the release of cytokines, chemokines, and leukocyte colony stimulating factors from human macrophages: role of glycosaminoglycans in inflammatory pathways of chronic venous disease. Curr Vasc Pharmacol 2014; 12: 173-185.

54. Lauver D.A., Booth E.A., White A.J., Poradosu E., Lucchesi B.R. Sulodexide attenuates myocardial ischemia/reperfusion injury and the deposition of C-reactive protein in areas of infarction without affecting hemostasis. J Pharmacol Exp Ther 2005; 312: 794-800.

55. Gabryel B., Jarząbek K., Machnik G., Adamczyk J,. Belowski D., Obuchowicz E., Urbanek T. Superoxide dismutase 1 and glutathione peroxidase 1 are involved in the protective effect of sulodexide on vascular endothelial cells exposed to oxygen-glucose deprivation. Microvasc Res 2016; 103: 26-35.

56. Matés J.M., Pérez-Gómez C., Núñez de Castro I. Antioxidant enzymes and human diseases. Clin Biochem 1999; 32: 595-603.

57. Lei X.G., Cheng W.H., McClung J.P. Metabolic regulation and function of glutathione peroxidase-1. Annu Rev Nutr 2007; 27: 41-61.

58. Kang P.M., Izumo S. Apoptosis in heart: basic mechanisms and implications in cardiovascular diseases. Trends Mol Med 2003; 9: $177-182$ 
59. Antalík M., Bona M., Gazová Z., Kuchár A. Spectrophotometric detection of the interaction between cytochrome $\mathrm{c}$ and heparin. Biochim Biophys Acta 1992; 1100: 155-159.

60. Spratte J., Meyer zu Schwabedissen H., Endlich N., Zygmunt M., Fluhr H. Heparin inhibits TNF- $\alpha$ signaling in human endometrial stromal cells by interaction with NF- $\kappa$ B. Mol Hum Reprod 2013; 19: 227-236.

61. Potter D.R., van Teeffelen J.W., Vink H., van den Berg B.M. Perturbed mechanotransduction by endothelial surface glycocalyx modification greatly impairs the arteriogenic process. Am J Physiol Heart Circ Physiol 2015; 309: 711-717.

62. Tiozzo R., Cingi M.R,. Pietrangelo A., Albertazzi L., Calandra S., Milani M.R. Effect of heparin-like compounds on the in vitro proliferation and protein synthesis of various cell types. Arzneimittelforschung 1989; 39: 15-20.

63. Park H.Y., Kang S., Kim G.Y., Jang Y., Kwon H.M., Shim W.H., Cho S.Y., Cho S.H. Inhibition of neointimal proliferation of rat carotid artery by sulodexide. J Korean Med Sci 1997; 12: 210214.

64. Urbanek T., Krasinski Z., Suminska-Jasinska K., Baum E., Borej-Nowicka G., Begier-Krasinska B., Breborowicz A. Sulodexide reduces the inflammatory reaction and senescence of endothelial cells in conditions involving chronic venous disease. Int Angiol 2016; 35; 140-147.

65. Jee J.P., Nam S.H., Park Y., Lee H.J., Park Y., Maeng H.J., Kim C.K. Simplified analysis of lipoprotein lipase activity: evaluation of lipasemic activity of low molecular weight heparin in rats. Arch Pharm Res 2012; 35: 1107-1114.

66. Fujita H., Fujishima H., Takahashi K., Sato T., Shimizu T., Morii T, Shimizu T., Shirasawa T,. Qi Z., Breyer M.D., Harris R.C., Yamada Y., Takahashi T. SOD1, but not SOD3, deficiency accelerates diabetic renal injury in C57BL/6-Ins2(Akita) diabetic mice. Metabolism 2012; 61: 1714-1724.

67. Oelze M., Kröller-Schön S., Steven S., Lubos E., Doppler C., Hausding M., Tobias S., Brochhausen C., LiH., TorzewskiM., WenzelP., Bachschmid M., Lackner K.J., Schulz E., Münzel T., Daiber A. Glutathione peroxidase-1 deficiency potentiates dysregulatory modifications of endothelial nitric oxide synthase and vascular dysfunction in aging. Hypertension 2014; 63: 390-396.

68. Aoyagi K., Kuzure Y., ShahrzadS., Hirayama A., NagaseS., UedaA. Inhibition by heparin of protein kinase $\mathrm{C}$ activation and hydroxyl radical generation in puromycin aminonucleoside treated isolated rat hepatocytes. Mol Cell Biochem 2003; 244: 3-9.

69. Olde Engberink R.H., Vogt L. The renoprotective effects of sulodexide. Drug Des Devel Ther 2016; 10: 1233-1234.

70. Saviano M., Maleti O., Liguori L. Double-blind, double-dummy, randomized, multi-centre clinical assessment of the efficacy, tolerability and dose-effect relationship of sulodexide in chronic venous insufficiency. Curr Med Res Opin 1993; 13: 96-108.

71. Coccheri S. Biological and clinical effects of sulodexide in arterial disorders and diseases. Int Angiol 2014; 33: 263-274.

72. Beebe-Dimmer J.L., Pfeifer J.R., Engle J.S., Schottenfeld D. The epidemiology of chronic venous insufficiency and varicose veins. Ann Epidemiol 2005; 15: 175-184.

73. Jawień A., Grzela T., Ochwat A. Prevelance of CVI in Poland. Phlebology 2003; 18: 110-122.

74. Golledge J., Quigley F.G. Pathogenesis of varicose veins. Eur J Vasc Endovasc Surg 2003; 25: 319-324.

75. Moyses C., Cederholm-Williams S.A., Michel C.C. Haemoconcentration and accumulation of white cells in the feet during venous stasis. Int J Microcirc Clin Exp 1987; 5: 311-320.
76. Raffetto J.D. Dermal pathology, cellular biology, and inflammation in chronic venous disease. Thromb Res 2009; 123: 66-71.

77. Andreozzi G.M. Role of sulodexide in the treatment of CVD. Int Angiol 2014; 33: 255-262.

78. Rabe E., Partsch H., Jünger M., Abel M., Achhammer I., Becker F., Cornu-Thenard A., Flour M., Hutchinson J., Issberner K., Moffatt Ch., Pannier F. Guidelines for clinical studies with compression devices in patients with venous disorders of the lower limb. Eur J Vasc Endovasc Surg 2008; 35: 494-500.

79. Perrin M., Ramelet A.A. Pharmacological treatment of primary chronic venous disease: rationale, results and unanswered questions. Eur J Vasc Endovasc Surg 201; 41: 117-25.

80. Cospite M., Ferrara F., Cospite V., Palazzini E. Sulodexide and the microcirculatory component in microphlebopathies. Curr Med Res Opin 1992; 13: 56-60.

81. Cospite M., Milio G., Ferrara F., Cospite V., Palazzini E. Haemodynamic effects of sulodexide in post thrombophlebitic syndromes. Acta Therapeutica 1992; 18: 149-161.

82. Coccheri S., Scondotto G., Agnelli G., Aloisi D., Palazzini E., Zamboni V., Venous arm of the SUAVIS (Sulodexide Arterial Venous Italian Study) Group. Randomised, double blind, multicentre, placebo controlled study of sulodexide in the treatment of venous leg ulcers. Thromb Haemost 2002; 87: 947-952.

83. Scondotto G., Aloisi D., Ferrari P., Martini L. Treatment of venous leg ulcers with sulodexide. Angiology 1999; 50: 883-889.

84. Kucharzewski M., Franek A., Koziolek H. Treatment of venous leg ulcers with sulodexide. Phlebologie 2003; 32: 115-120.

85. Zou Y-X., Feng X., Jing Z-P. Efficacy and safety of sulodexide in the treatment of venous ulcers of legs. Pharm Care Res 2007; 7: $22-24$.

86. Kearon C., Kahn SR., Agnelli G., Goldhaber S., Raskob G., Comerota A.J. American college of chest physicians. Antithrombotic therapy for venous thromboembolic disease: American college of chest physicians evidence-based clinical practice guidelines (8th edition). Chest 2008; 133: 454-545.

87. Andreozzi G.M., Bignamini A.A., Davì G., Palareti G., Matuška J., Holý M., Pawlaczyk-Gabriel K., Džupina A., Sokurenko G.Y., Didenko Y.P., Andrei L.D., Lessiani G., Visonà A. SURVET Study Investigators. Sulodexide for the Prevention of Recurrent Venous Thromboembolism: The Sulodexide in Secondary Prevention of Recurrent Deep Vein Thrombosis (SURVET) Study: A Multicenter, Randomized, Double-Blind, Placebo-Controlled Trial. Circulation 2015; 132: 1891-1897. 